\title{
ARTICLES
}

\section{Are Sentient Beings Replaceable?}

By "sentient beings", I mean creatures that are sentient or conscious, but not rational and self-conscious. They are not persons in the Lockean sense who can reason and see themselves as beings with a past and a future.

This classification of beings is intended to be non-speciesist: species is irrelevant as far as membership in the class of sentient beings is concerned. Animals such as chickens are sentient beings, and so are humans such as fetuses, new-born infants, and defective adults. Perhaps there are animals such as chimpanzees who are persons and not sentient beings.

A currently fashionable view is that sentient beings are replaceable. ${ }^{1}$ On this view, there is nothing wrong with painlessly killing a happy sentient being provided it is replaced with another such being. My main target in this paper is this replacement view, particularly as it is defended by Peter. Singer. I begin with a consideration of the replaceability argument that singer uses to defend his view. Then I claim that Singer has an objectionable receptacle view of sentient beings. Finally, I argue that replacement does not make killing a sentient being morally permissible.

\section{1}

To begin with, let us consider Singer's "replaceability argument." This argument is initially stated as a limited defense of rearing animals for food. But more is at stake than just meat-eating: Singer goes on to give the argument as a defense of human abortion and infanticide. Here is the argument:

Although meat-eaters are
responsible for the death of
the animal they eat and for the
loss of pleasure experienced by
that animal, they are also
responsible for the creation of
more animals, since if no one
ate meat there would be no
more animals bred for fatten-
ing. The loss meat-eaters
inflict on one animal is thus
balanced, on the total view, by
the benefit they confer on the
next. We may call this 'the
replaceability argument'.

Now Singer is generally opposed to meat-eating on utilitarian grounds: it wastes resources and it produces pain and suffering for animals. In line with this general attack, he proceeds to make two points which he claims weaken the replaceability argument as a defense of meat-eating. The first is that it would not justify eating the flesh of animals reared in factory farms because their lives are to themselves more of a burden than a benefit. This point is well-taken. But the argument can still be used to justify eating the flesh of happy animals. Singer himself admits that if chickens can be killed painlessly, and for economic reasons they could not be reared if we did not eat them, then "the replaceability argument will justify killing the birds, because depriving them of the pleasures of their existence can be offset against the pleasures of chickens who do not yet exist, and will exist only if existing chickens are killed."

Singer's second point about the argument is as follows:

A second point is that if it is 
good to create life, then presumably it is good for their to be as many people on our planet as it can possibly hold. With the possible exception of arid areas suitable only for pasture, the surface of our globe can support more people if we grow plant foods than if we raise animals. ${ }^{4}$

This point is questionable. Why is it good to create life? This doesn't follow from the replaceability argument or from the total view version of utilitarianism assumed in the argument. And why is it good for their to be as many people as possible? This doesn't follow either; in fact, it seems unlikely that having as many people as possible will produce the greatest quantity of pleasure. Finally, even granting Singer's assumptions, it does not follow that the best way to support more people is by growing plant food rather than animals. Increased production of certain animals for food might possibly be the best way to support more people.

\section{II}

Thus far the replaceability argument remains undefeated as a limited defense of meat-eating. In this section, I want to raise some more fundamental objections.

Are sentient beings really replaceable? That is the main issue. Singer recognizes this, for he goes on to cite a persuasive objection given by Henry Salt, the nineteenth-century English vegetarian. According to Salt, the fallacy of the argument is that it compares existence with non-existence, and this is nonsense. The happiness of a being who exists cannot be sensibly compared to the happiness of a non-existent being.

Singer notes that when he wrote Animal Liberation he accepted Salt's view. But now he is less confident. What bothers him is our intuitions about bringing beings into existence: if we think it bad knowingly to bring a miserable being into existence, then why don't we think it good knowingly to bring a happy being into existence? On the total view which singer accepts, it seems that it would be good to bring happy beings into existence, since that is one way to produce a greater total of pleasure. So on this view, the happiness of nonexistent beings can and should be considered, and compared to the happiness of existing beings.

Singer is not very confident about this appeal to vague intuitions. So he tries to reply to Salt's objection in a different way. His reply depends on dividing beings into two groups: sentient beings and persons. Persons are rational and self-conscious beings, while sentient beings are merely conscious. Salt's view correctly applies to persons, Singer says, but it does not apply to mere sentient beings. But why not? Singer maintains that the existence or non-existence of a sentient being can be left out of the utilitarian calculation; all that needs to be considered is pleasure or happiness, both actual and possible, and their is nothing nonsensical about doing that. What do we say about the beings themselves then? Singer's answer is that they are mere containers of experiences, or "receptacles:"

Beings that are conscious, but not self-conscious, on the other hand, can properly be regarded as receptacles for experiences of pleasure and pain, rather than as individuals leading lives of their own. ${ }^{5}$ But just how are sentient beings receptacles? Singer explains it in the following way:

The total version of utilitarianism regards sentient beings as valuable only in so far as they make possible the existence of 
intrinsically valuable experiences like pleasures. It is as if sentient beings are receptacles of something valuable and it does not matter if a receptacle gets broken, so long as their is another receptacle to which the contents can be transferred without any getting spilt. ${ }^{6}$

This receptacle view involves a strange view of experiences and subjects of experiences. It talks about experience being "transferred" to a different subject like water being poured from one glass to another. This is nonsense on the face of it. On our ordinary conception, experiences necessarily belong to the subject who has them--my pain is mine and not somebody else's, and it does not make sense to say that my pain can be "transferred" to another subject. As for subjects of experience, it is very odd to say that they are mere "receptacles" of experience, as if they had no awareness of them.

Singer's adoption of this view gives him another problem. He does not want to apply it to persons, but why not? Why aren't persons just receptacles of experience that happen to hold more. "contents" than sentient beings? On preference utilitarianism, the version of utilitarianism that Singer applies to persons, the interests of persons are taken into account. But this sort of utilitarianism seems to treat persons as mere receptacles of intrinsically valuable satisfied interests just as the total view treats sentient beings as receptacles of intrinsically valuable pleasures. The trouble is that once utilitarianism has picked out certain things as intrinsically valuable, the subjects who have them or "contain" them become morally insignificant; they are mere means rather than ends in themselves. The classical remedy to this neglect of subjects, of course, is to insist that they are ends in themselves having an intrinsic value apart from their experiences.

In any event, Singer has not given a satisfactory reply to Salt's objection about comparing existence with nonexistence. The appeal to vague intuitions about bringing beings into existence is not very convincing, as Singer admits. And the objectionable receptacle view, once adopted, seems to apply to persons as well as sentient beings; this produces the unhappy result that the replaceability argument applies to persons as well as sentient beings.

\section{III}

In the last section, I objected to Singer's receptacle view of sentient beings. It turns out that Singer has another way of making the distinction between persons and sentient beings, namely what he calls "the test of universalizability:"

The test of universalizability supports this view [the receptacle view]. If $I$ imagine myself in turn as a self-conscious being and a conscious but not self-conscious being, it is only in the former case that I could have a desire to live in addition to a desire for pleasurable experiences. Hence it is only in the former case that my death is not adequately compensated for by the creation of a being with similar prospects of pleasurable experiences. $^{7}$

From this it looks like the desire to live is what marks the morally significant dividing line between persons and sentient beings, and not rationality and self-consciousness. For the sake of clarity, let me reformulate the argument contained in this passage, using "sentient being" to mean "conscious but not self-conscious being," 
and "similar replacement being" to mean "being with similar prospects of pleasurable experiences;"

(1) A sentient being does not have a desire to live.

(2) If a sentient being does not have a desire to live, then its death is adequately compensated for by the creation of a similar replacement being.

(3) Hence its death is adequately compensated for by the creation of a similar replacement being.

The truth of premiss (1) depends on the meaning of "a desire to live." If this means an unconscious urge to stay alive, then it seems possible that sentient beings do have such a desire. On the other hand, if this means a conscious preference to live in the future, then only persons can have this desire. Still it should be noted that plenty of persons do not have a conscious desire to live in the future. Would it be wrong painlessly to kill such a person? Suppose doing this does not violate any conscious preference. And it produces good side effects for others. The person killed can also be replaced by another and happier person. It looks like the replaceability argument could be used to justify painlessly killing such a person. Or at least Singer does not rule this out.

Premiss (2) also needs to be interpreted. What does singer mean by "adequate compensation?" Obviously it is not compensation in the form of a benefit to someone wronged, for the sentient being killed receives no such benefit. Singer's examples make it clear enough that what he has in mind is a sort of impersonal compensation in the form of a moral balance where the loss of good is balance by a gain of good. Thus when he discusses replacing chickens for food, he says that the loss of pleasure resulting from killing the chickens is offset by the gain in pleasure produced by the creation of new chickens. ${ }^{8}$ Similarly, he claims that the loss of happiness produced by killing a fetus or an infant is offset by the gain of happiness resulting from the birth of a similar fetus or infant.

Consider one of Singer's examples, a case of abortion for convenience:

Suppose a woman has been planning to join a mountainclimbing expedition in June, and in January she learns that she is two months pregnant. She has no children at present, and firmly intends to have a child within a year. The pregnancy is unwanted only because it is inconveniently timed. Opponents of abortion would presumably think an abortion in these circumstances particularly outrageous, for neither the life nor the health of the mother is at stake--only the enjoyment she gets from climbing mountains. Yet if abortion is wrong only because it deprives the world of a future person, this abortion is not wrong; it does no more than delay the entry of a person into the world. ${ }^{9}$

In this example, replacement does not merely provide a moral balance of the sort we have been discussing, it also makes killing a sentient being not wrong; it makes this morally permitted even for the sake of convenience.

But is this abortion not wrong as Singer says? It is not very plausible to say that it is wrong only because it deprives the world of a future person, as if no one is killed. Even at two months, the fetus has a brain and can feel pain and pleasure. Isn't killing this fetus deliberately and painfully wrong? Certainly it is wrong from a non-utilitarian viewpoint: it is wrong intentionally and painfully to kill an innocent human 
being merely for the sake of convenience.

But is it wrong according to the total view, the version of utilitarianism that Singer applies to sentient beings? The answer is not so obvious. We have to estimate the good and bad effects of the abortion, and try to determine if the abortion produces a greater quantity of pleasure than the alternative of not getting an abortion. Suppose that the loss of pleasure resulting form the death of one fetus is exactly balanced by a gain in pleasure produced by the creation of another fetus when the mother gets pregnant again. Presumably, this is what Singer has in mind. It doesn't follow from this that the abortion is not wrong. The alternative of not getting an abortion would not produce this loss of pleasure. Why isn't this morally better? Also the abortion itself produces pain for the fetus and the mother, while the alternative does not do this. Furthermore, there are side effects on the mother and others to be considered. Surely the abortion will produce bad effects on the mother such as guilt, anxiety about getting pregnant again, and so on. What about the husband, assuming there is one? Wouldn't there be bad effects on him, particularly if he wanted the first child? Perhaps there will also be bad effects on the doctors and nurses too; perhaps relatives will be affected. All these bad effects have to be weighed against the good effect on the mother: she gets to enjoy her climbing trip. All things considered, it seems likely that the bad effects of the abortion outweigh the good effects, and that the alternative of not getting an abor- tion is morally preferable. If so, the abortion is wrong, even according to the total view accepted by Singer.

To conclude: Singer has not shown that replacement provides adequate compensation for painfully killing a sentient being in the sense of making it not wrong. 10

\author{
James E. White \\ St. Cloud State University
}

\section{NOTES}

1 See Jonathan Glover, Causing Death and Saving Lives (Middlesex, England: Penguin Books, 1977), P. 159; and Peter Singer Practical Ethics (Cambridge: Cambridge. University Press, 1979), Chapter 5.

2 Singer,op. cit., p. 100.

3 lbid., P. 104.

4 lbid., P. 100.

5 lbid., p. 102.

6 lbid., p. 100.

7 Ibid., P. 102.

s Ibid., p. 104.

g Ibid., p. 121.

10 I am grateful to the referees for Ethics \& Animals for helpful comments on an earlier draft of this paper. 